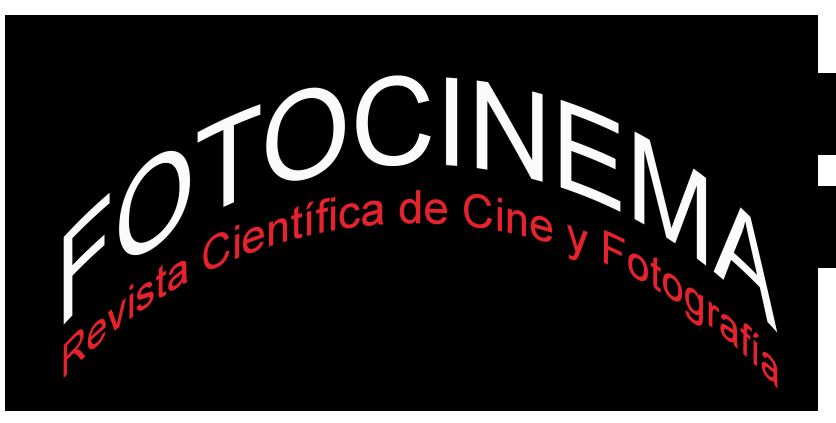

\title{
RELACIÓN SIMBIÓTICA ENTRE PINTURA Y CINE EN EL MATTE PAINTING
}

\section{SYMBIOTIC RELATIONSHIP BETWEEN PAINTING AND CINEMA IN MATTE PAINTING}

Darío Lanza Vidal

Universidad Rey Juan Carlos y Transforming Arts Institute de España

dario@dariolanza.com

\section{Resumen:}

En el presente artículo queremos poner nuestra atención en un particular recurso de la construcción cinematográfica, el matte painting, un efecto especial que en pocas ocasiones ha recibido suficiente atención por parte de investigaciones de carácter teórico pero que sin embargo se presenta como una materia particularmente sugestiva en la que se recurre a la sinergia entre lo pictórico y lo fílmico para la elaboración de una imagen híbrida producto de la colaboración simbiótica entre ambos medios. A lo largo del presente artículo comprobaremos cómo en un plano con matte painting se activa un complejo diálogo entre pintura y cine, una relación de aportes mutuos donde la pintura contribuye incorporando todo aquello que la cámara no alcanza a retratar y el cine aporta certificado de realidad a lo pintado. Y será en el seno de este contexto donde encontramos una de las relaciones más íntimas, si no la más íntima, de cuantas se establecen entre cine y pintura.

\begin{abstract}
:
In this paper we want to focus on a particular resource of the cinematographic construction, matte painting, a special effect that very few times has received sufficient attention by theoretical investigations but which nevertheless appears as a particularly suggestive subject in which the synergy between the pictorial and the film is used for the elaboration of a hybrid image resulting from the symbiotic collaboration between both media. Throughout this article we will see how in a shot with matte painting we can find a complex dialogue between painting and cinema, a relationship of mutual contributions where painting contributes incorporating everything that the camera fails to portray and film provides a certificate of reality to the painted image. And it will be in this context where we find one of the most intimate, if not the most intimate, relationships of those established between cinema and painting
\end{abstract}

Palabras clave: Matte painting; pintura; cine; interrelaciones; sinergia; simbiosis.

Keywords: Matte painting; painting; cinema; interrelations; synergy; symbios 
Cómo citar: Lanza, D. (2018). Relación simbiótica entre pintura y cine en el matte painting. Fotocinema. Revista científica de cine y fotografía, $n^{0} 16$, pp. 153-172.

Disponible: http://www.revistas.uma.es/index.php/fotocinema/

DOI: http://dx.doi.org/10.24310/Fotocinema.2017.voi16

\section{Introducción}

El término matte painting ${ }^{1}$ se utiliza para describir una técnica adscrita al contexto de los efectos especiales empleada para la simulación de entornos cinematográficos por medio de material pictórico. Imágenes tan memorables como el suntuoso hall de la mansión de Nana (Jean Renoir, 1926), las vistas de Tara en Lo que el viento se llevó (Gone with the Wind, Victor Flemming, 1939), las asfixiantes alcantarillas en la secuencia final de El tercer hombre (The Third Man, Carol Reed, 1949), la Roma de Espartaco (Spartacus, Stanley Kubrick, 1960) o el célebre plano final en la playa de El planeta de los simios (Planet of the Apes, Franklin J. Schaffner, 1968) nos confrontan ante la evidencia de con cuánta frecuencia como espectadores cinematográficos nos hallamos en realidad contemplando una pintura, creaciones que suturan las artes cinematográfica y pictórica a través de un sofisticado diálogo entre ambos medios en el seno mismo del fotograma.

Situándose en el vértice intersección entre lo pictórico y lo fílmico, el matte painting se presenta como una materia particularmente sugestiva que vehicula en una misma imagen las particularidades de la imagen fílmica y la pictórica y realiza su aporte significante a partir de la sinergia entre ambas.

\footnotetext{
${ }^{1}$ El término significa literalmente "pintura máscara" debido a que las primeras formas de matte painting consistían en un cristal situado entre la cámara y la escena a filmar, el cual, merced a su transparencia, permanecía completamente invisible a la cámara al tiempo que permitía la incorporación de una pintura en su superficie, pintura que por su propia presencia sobre el cristal, ocultaba o enmascaraba aquellos elementos reales que se deseaban reemplazar, de modo que operaba al mismo tiempo como representación y como máscara.
} 
Un fenómeno capaz de movilizar el concurso simbiótico de estos dos medios y que nos invita a reflexionar y profundizar en las particulares relaciones que es capaz de activar y en el modo en que moviliza un conjunto único de aportes mutuos que resulta imperativo poner en valor.

En el presente artículo planteamos una reflexión sobre las características de las singulares relaciones que se establecen en el interior de un plano con matte painting y para ello comenzaremos recordando el ya tradicional debate sobre cine y pintura y las principales posturas de aquellos autores que han reflexionado sobre ambos medios. Desde este punto de partida nuestro análisis principal nos conducirá a desvelar cómo las estrechas relaciones entre cine y pintura activadas en el matte painting pueden describirse en términos de subordinación en el plano instrumental, de simbiosis en lo relativo al aporte significante, hasta alcanzar el estatus de mímesis en la percepción, relacionándose allí hasta la completa identificación. Una vez expuestas las características de estas relaciones abordaremos la cuestión del realismo y plantearemos la posición del matte painting en torno al fotorrealismo como movimiento pictórico, para finalizar reivindicando la propia figura del matte painter como artista plástico de pleno derecho.

En el presente estudio nos centraremos en las formas tradicionales de matte painting, aquellas desarrolladas a mano mediante pinceles pues, si bien los planteamientos teóricos son compartidos con las actuales metodologías digitales, es en aquellas fórmulas tradicionales donde encontramos más vivas las analogías con la praxis pictórica.

\section{El tradicional debate sobre las interrelaciones entre cine $\mathbf{y}$ pintura}

Descrito en los términos anteriores podemos ver que el matte painting establece una particular conexión entre una materia propia del arte pictórico y otra propia del cinematográfico, dos medios que aquí van a relacionarse con una especial intensidad. Parecería que a estas alturas una reflexión sobre las relaciones entre cine y pintura podría resultar redundante dado el 
número de autores que, como Eisenstein (1989), Aumont (1997) o Mitry (2002), y aquí en España como Rafael Cerrato (2010) o incluso José Luis Borau (2003), han ya reflexionado sobre las influencias y tensiones entre ambas artes. De entre los diversos estudios acerca de este debate únicamente mencionaremos aquí, por particularmente radical, la postura de Eisenstein, quien considera al cine como la forma de "arte total" (Eisenstein, 1989, p. 316), como un medio artístico tecnológicamente más evolucionado, equivalente a la versión de nuestro tiempo de la pintura aunque dotado de más recursos y capacidades expresivas que esta. Desde otro prisma lo ve un teórico como Aumont (1997), quien frente a la concepción evolucionista eisensteniana, defiende la autonomía de cine y pintura como dos medios expresivos de pleno derecho, independientes y con recursos propios, en posición de igualdad en la historia de la representación visual:

[...] que la relación entre pintura y cine no fluye en sentido único, que no es una descendencia ni una digestión, ni siquiera cuando a veces el cine, y ésta es otra historia, ha pretendido ser heredero de la pintura o, peor aún, ha dado a veces la impresión de regurgitarla; no es en ningún caso la recuperación de formas que hubiesen surgido totalmente armadas del cerebro de los pintores. (pp. 29-30)

Inclinándonos en este artículo más hacia la postura de independencia expresiva de Aumont que hacia la concepción eisensteniana de "filiación unilineal pintura-foto-cine" (Aumont, 1997, p. 31), resultan sin embargo evidentes las poderosas conexiones que ambas artes, como medios autónomos y por tanto también mutua y legítimamente influenciables, han mantenido a lo largo de su siglo de coexistencia. No tenemos más que recordar a José Luis Borau (2003) y sus dos discursos sobre el tema en los que desarrolla una particular enumeración de los modos en que la pintura ha ejercido presencia e influencia en el medio cinematográfico, incluyendo desde la inspiración formal de un film en una obra pictórica como referente en lo relativo a puesta en escena, composición, ambientación, iluminación o fotografía; la participación de un artista en el diseño o la dirección artística de una película, citemos el caso célebre de Dalí para Recuerda (Spellbound, 
Alfred Hitchcock, 1945); hasta la influencia estilística de una escuela pictórica en un director, pensemos en Gance, Eisenstein, Rohmer, Godard, o en todo un movimiento cinematográfico, como representaría el caso del cine surrealista o del expresionismo alemán; sin olvidar los casos más explícitos de presencia física de un cuadro en un film, la dramatización de la biografía de un pintor o los ejemplos de tableau vivants como citas o representaciones más o menos literales de una obra pictórica dentro de una película, recordemos la cena de Viridiana (Luis Buñuel, 1961). De forma simétrica, Borau recoge también las formas en que el cine ha afectado a la práctica pictórica, desde la mera inclusión de elementos del universo cinematográfico, actores, lugares, objetos, en ciertas pinturas, pensemos en la obra de Warhol sobre actores y actrices de Hollywood, a una influencia más profunda en la concepción pictórica formal, como la forma más libre de entender la iluminación o la imitación en el lienzo de efectos genuinamente fotocinematográficos como el desenfoque, los efectos de lente o la sobreimpresión de imágenes. También la particular visión de la cámara de cine ha modificado la composición en la pintura, que ha pasado a incorporar desencuadres, formatos panorámicos, tamaños de plano y recursos importados del medio cinematográfico, como el plano-contraplano. El rasgo más característico de la imagen cinematográfica, el movimiento, también se ha tratado de incorporar a la imagen pictórica, que ha buscado fórmulas cinéticas de trascender a su propio estatismo. A través de todos estos indicios resulta fácil detectar la enérgica influencia que el cine ha ejercido en prácticamente todos los movimientos artísticos recientes, desde el futurismo y surrealismo a los más contemporáneos expresionismo abstracto o pop art (Borau, 2003). En términos similares Zunzunegui (2010) también describe las influencias y préstamos entre fotografía y pintura cuando señala cómo la fotografía toma de la pintura el formato de la imagen, los temas y una visión común del mundo, mientras por su parte la pintura incorpora hallazgos fotográficos como "el gusto por el fragmento, los estudios de movimiento, la preocupación por los efectos luminosos o el interés por los aspectos más humildes y secretos de lo cotidiano" (p. 134). 


\section{La cuestión del matte painting. De la subordinación a la simbiosis entre cine y pintura}

El análisis tradicional sobre este tema, como los anteriormente citados, contempla las mencionadas relaciones desde posturas algo distantes respecto al hecho pictórico y cinematográfico. Por contra, y dejando constancia de los citados catálogos de influencias mutuas, una aproximación más pormenorizada al fenómeno nos permite descubrir que la relación entre cine y pintura en pocos casos se presenta de forma tan íntima como lo hace en el matte painting. Si Aumont (1997) identifica a la luz y al color como incorporaciones de lo pictórico en lo fílmico, en el matte painting encontramos la mayor inscripción posible de lo pictórico en lo fílmico, donde la palabra clave es, obviamente, “en”, pues apuntamos a una total inmersión de la sustancia pictórica dentro de la propia materia fílmica, inmersión que veremos a continuación va a activar un nuevo catálogo de relaciones constructivas (F1).

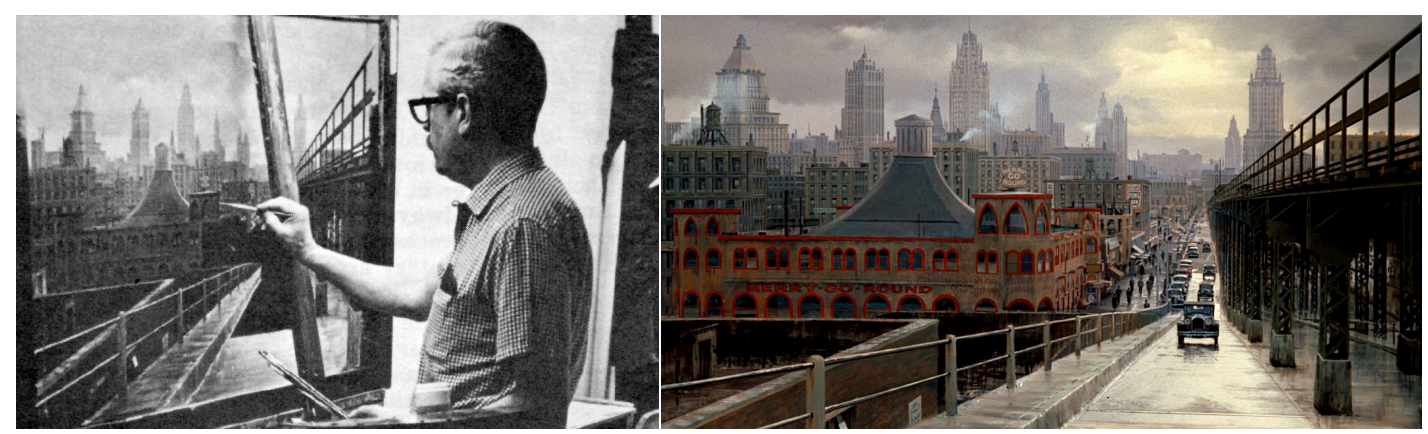

F1. Matte painting de Albert Whitlock en El golpe (The Sting, George Roy Hill, 1973).

Una primera mirada a las relaciones que aquí se establecen nos permite apuntar a una cierta anterioridad de lo filmado frente a lo pintado en el matte painting para aludir al modo en que la pintura se supedita al material rodado para heredar de él sus coordenadas geométricas y aspectuales. Debido a esta obligada coordinación geométrica entre los dos fragmentos que van a suturarse, es habitualmente la pintura, debido a su superior flexibilidad plástica, quien se subordina a las características del fragmento rodado. Por ejemplo, para la pintura el punto de vista no es libre, le es impuesto, prefijado en el elemento rodado, de quien debe tomarlo previamente a la 
construcción de su imagen. La pintura por tanto se construye con posterioridad a la filmación, o cuando menos a la elección principal del encuadre, y condiciona su realización a las particularidades de aquella. De este modo la pintura se construye a partir de los parámetros topográficos presentes en el material rodado, permitiendo elaborar un fragmento pictórico no diríamos que idéntico pero sí afín al escenario físico preexistente. La pintura logra así subordinarse de una forma tan eficaz que el fragmento rodado parece subsumirla e incorporarla a su propia materia. El matte painting consigue tratar esta interconexión como una continuidad, asimilando las dos imágenes representadas como adyacentes y anexionándolas como un continuum. Heredando las coordenadas espaciales de perspectiva y punto de vista, y aspectuales de iluminación, color y enfoque, inscritas en la imagen filmada, lo pintado se imbrica sobre aquella y la prolonga, como dos realidades deslizándose una sobre otra, diferentes pero íntimamente interrelacionadas. La imagen pintada consigue así una mímesis con la filmada, activando una relación de identidad como representaciones de una misma y única realidad que nunca ha existido.

De hecho, si la nomenclatura del análisis cinematográfico emplea habitualmente el término "cuadro fílmico" para definir el contenedor de la representación cinematográfica por semejanza con el "cuadro pictórico", aquí dicha relación sobrepasa la mera semejanza hasta la completa identidad: el cuadro pictórico del segmento pintado y el cuadro fílmico de lo rodado presentan tal cantidad de similitudes, en tamaño, formato, color, motivo, iluminación, sombreado, punto de vista y perspectiva, que una vez yuxtapuestos resultan indistinguibles.

Por supuesto, esta subordinación de la pintura a lo rodado es una reserva meramente operativa e instrumental, derivada de la mayor ductilidad plástica de la pintura como medio, pero no se transfiere con posterioridad al cuadro fílmico, en el que, a nivel significante, ambas se muestran como entidades perfectamente equivalentes hasta el punto de indisociables. De hecho ninguna de las dos imágenes constituyentes es capaz de remitir por 
separado a una entidad diegética, sino que es la resultante de la combinación de ambas la que finalmente apunta a una realidad en la diégesis. Merced a la sutura operada en el matte painting, la imagen pintada, plana, deslocalizada y por tanto abstracta, se adhiere al escenario físico y hereda de él existencia efectiva. La imagen bidimensional se tridimensionaliza durante su mímesis con el escenario filmado, para luego junto a él ser bidimensionalizada de nuevo por el proceso escópico-registrador de la cámara que inaugura la nueva imagen. Vemos por tanto una pintura convertirse, por los mecanismos ilusionistas activados por el matte painting, en escenario, para a continuación convertirse, ahora ya por obra del mecanismo de identificación de la narración fílmica, en mundo dentro del universo diegético.

Pero las relaciones que se establecen aquí entre estos dos medios van mucho más allá de la aparente subordinación instrumental orientada a la mímesis que acabamos de citar. En el matte painting, pintura y cine establecen de facto una relación que se aproxima mucho más a lo simbiótico en torno a un activo aporte mutuo de significados complementarios, más recíproco e íntimo que los que encontramos en otros contextos. Como sabemos, el matte painting opera dividiendo el cuadro en dos áreas dispares en cuanto a naturaleza y origen que pasan a identificarse hasta la unificación mediante la negación de las diferencias entre las materias pictórica y fílmica y el intercambio mutuo de significados. Las diferencias entre los dos signos desaparecen y entre ambos se construye una tercera instancia significante resultado de su unión. Los dos fragmentos que entran en contacto establecen una red de relaciones de interdependencia donde la pintura, empleada como constructora de espacios, paisajes y arquitecturas, contribuye contextualizando la acción y el relato en un lugar y un tiempo, mientras que la imagen fílmica contextualiza a la pintura en el transcurso de la propia historia. La pintura ayuda a situar geográfica y temporalmente la acción mediante la creación del ambiente y el entorno en el que esta se inscribe mientras que por su parte la acción filmada proporciona un aporte narrativo sin el cual lo pintado se hallaría desconectado del relato. 
Operando en el vértice entre las prácticas pictórica y cinematográfica y equidistante entre ambas, el matte painter importa de la práctica pictórica tanto el estilo, se habla por ejemplo del impresionismo de la técnica de Albert Whitlock, como los materiales, empleando pigmentos al óleo o acrílicos. Pero el principal aporte de la pintura, y esta es la razón de ser del matte painting, es la incorporación en la imagen fílmica de todo aquello que la cámara no alcanza a retratar. Todo lo que resulta imposible construir o reproducir físicamente es sin embargo susceptible de ser dibujado e incorporado al flujo fílmico como un elemento pintado. Si Aumont (1997) considera que la principal ventaja de la pintura frente al cine radica en que aquella dispone de "unos medios de acceder a una emoción, a un sistema de las emociones más directo, más seguro" (p. 127), una superioridad, por tanto, en lo emocional, la cualidad mediante la que la pintura realiza aquí su verdadero aporte es su ilimitada flexibilidad plástica, su omnipotencia representativa, gracias a la cual es capaz de incorporar en la imagen cualquier motivo imaginable sin restricciones de índole logístico o económico allí donde la captura fílmica encuentra siempre mayores condicionamientos. Diríamos que la pintura, con su ilimitada capacidad de representación, viene a aportarle a la imagen cinematográfica una radical ampliación de la esfera de lo representable (F2).
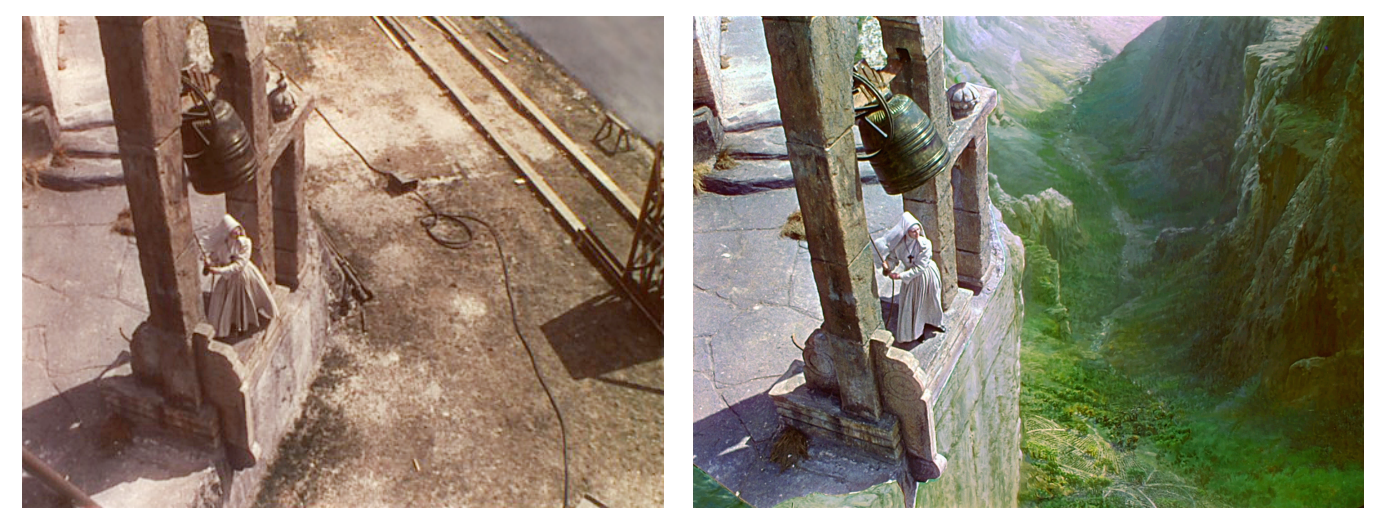

F2. Matte painting de Walter Percy Day en Narciso Negro (Black Narcissus, Michael Powell, 1947).

Por su parte, la presencia del fragmento rodado aporta realidad a lo pintado. Tras la sutura, la imagen resultante se percibe como un signo icónico único al que el espectador atribuye origen fotográfico. Gracias a la yuxtaposición con la imagen fílmica, la pintura, representación que no implica referente, deja 
de ser una creación imaginaria y adquiere automáticamente naturaleza indicial, se convierte en huella de un supuesto referente real. Gracias a esta transferencia de realidad, la imagen pintada adquiere, por ósmosis, naturaleza indicial, hereda carta de realidad. Merced a esta relación simbiótica con la imagen fílmica podemos afirmar, utilizando una expresión de Zunzunegui (2010), que el referente de la pintura deja de ser "algo facultativamente real para convertirse en algo necesariamente real” (p. 132). La imagen pintada abandona así el orden de lo icónico y se incorpora al orden del índex, se transforma de icono manufacturado en huella de una realidad, como diría Dubois (1994). Asistimos a la transformación, al menos en la percepción del espectador, de signo gráfico de naturaleza pictórica en material genuinamente fotográfico. La imagen fílmica, en virtud de la cualidad constatativa que le atribuimos dada su génesis mecánica, autentifica a la pintura y le otorga certificado de realidad, de modo que todo lo que distinguía a ambas imágenes desaparece. El dispositivo del matte painting funciona gracias a las dos cualidades que se intercambian aquí: la ilimitada flexibilidad de representación de la pintura y la condición indicial del cine como mecanismo gráfico. Un medio permite una representación omnipotente y el otro aporta certificado de realidad a lo representado, principios entre los que discurre la efectividad del matte painting como recurso.

Además de certificado de realidad, la imagen fílmica consigue insuflar un dinamismo de facto en la pintura, la cual se aleja de su configuración inmóvil para activarse en signo dinámico. La no-linealidad del signo pictórico pasa a articularse dentro de la temporalidad del signo cinematográfico, que lo absorbe e incorpora a su propio flujo. La materia fílmica convierte la imagen pictórica en "imagen-movimiento", empleando el término de Deleuze (1984). El movimiento, la cualidad más específica de la imagen cinematográfica, se vuelve aquí transferible, contagiable, y es incorporado al material pictórico. Se trata por supuesto de una ilusión de movimiento, pues en todo momento la relación se establece entre dos signos icónicos completamente estáticos al practicarse la sutura a nivel del fotograma, espacio donde la imagen fílmica 
es también imagen estática. El movimiento se genera para ambos y se contagia a la pintura a partir de la restitución de la continuidad temporal que proporciona el flujo fílmico. Naturalmente los signos en la pintura no adquieren movimiento per se, pero tampoco son percibidos con el estatismo que les es propio, diríamos que adquieren un movimiento de facto, si acaso mental. Tras esta activación del movimiento en la pintura, el matte painting se instituye verdaderamente como "cine pintado" (F3).

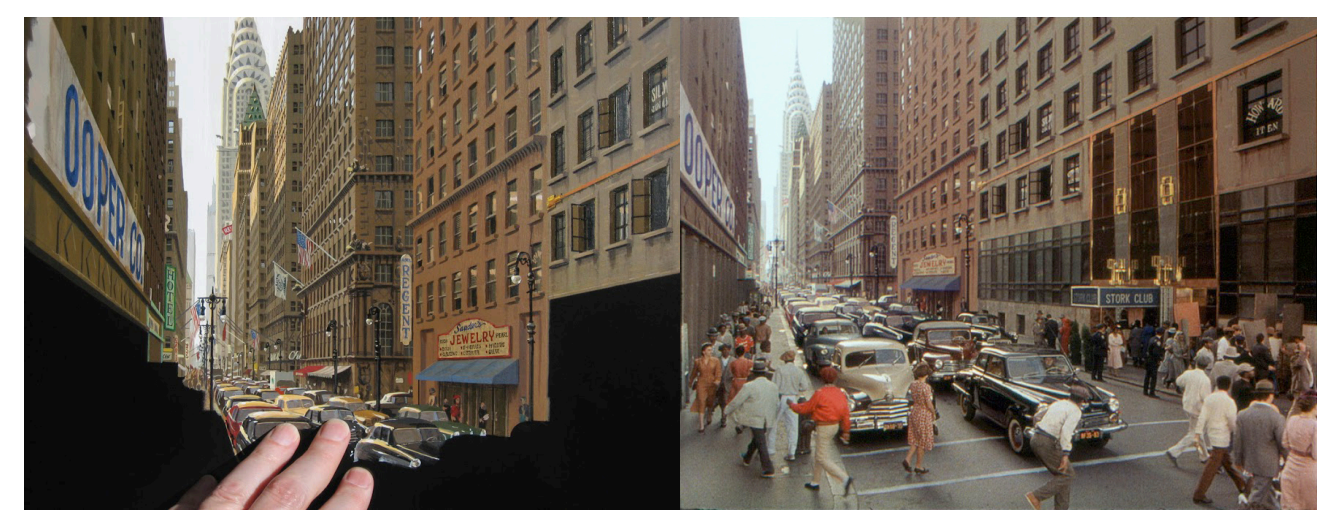

F3. Matte painting de Ken Marshell en The Josephine Baker Story (Brian Gibson, 1991).

\section{De la simbiosis a la mímesis entre pintura y cine. Fotorrealismo y pintura "cinerrealista"}

Con frecuencia se recurre al término realismo para apuntar a la vocación naturalista y mimética del matte painting, a su carácter analógico, entendiendo este término como la semejanza o analogía del icono con el objeto representado. Sin embargo el término realismo resulta excesivamente ambiguo, máxime en el contexto cinematográfico donde siempre ha suscitado debate. En torno al matte painting hablar de realismo resulta a todas luces inadecuado al no establecerse semejanza alguna con el objeto representado, dado que no existe el objeto que se muestra en la representación. No olvidemos que el matte painting se emplea generalmente para incorporar al film elementos, lugares y entornos con frecuencia inexistentes, por lo que no existe el objeto con el que evaluar la semejanza. En lugar de mirar a la realidad, el matte painting reproduce elementos 
pertenecientes a la realidad diegética al mismo tiempo que va construyendo dicha realidad diegética con sus representaciones. Podemos decir, utilizando una expresión de Lévi-Strauss, que el matte painting constituye una "representación realista de un modelo inexistente" (recogido en Zunzunegui, 2010, p. 117). El carácter analógico del matte painting lo que en realidad establece es una analogía con la idea mental de dicho objeto, es más, con la idea mental del aspecto que una fotografía o filmación mostraría de dicho objeto en caso de existir. Por esta razón resultará mucho más adecuado inscribir al matte painting dentro de la esfera del fotorrealismo, concepto con el que se encuentra ciertamente más relacionado.

En términos generales, por fotorrealismo se entiende un movimiento artístico postpop desarrollado a partir de la década de 1960 por artistas como Richard Estes o Chuck Close que reivindica un arte figurativo y naturalista. El fotorrealismo no mira a la realidad sino a la fotografía como su referente y trata de imitar la particular representación de la cámara fotográfica². De igual modo, el matte painting, en su ambición por mimetizarse con el metraje capturado por la cámara, busca principalmente la imitación de una representación fotográfica, en este caso de la que produce el cine. Parafraseando el célebre planteamiento de Bazin (2008) encontraríamos aquí al matte painting como "asíntota de la imagen fotográfica”, aquello a lo que el matte painting mira como referente y a lo que aspira a aproximarse hasta la identificación. Constituye este por tanto una representación pictórica manual que intenta parecer creada por una cámara, el hombre imitando a la máquina, lo que legitima la inscripción del matte painting en la órbita del fotorrealismo como práctica artística. Efectivamente, y este es un punto clave, en el matte painting la pintura no trata de parecer real, como ocurre

2 Quisiéramos destacar aquí la diferencia entre los conceptos, con frecuencia entremezclados, de "fotorrealismo", como la imitación de la representación fotográfica, y de "hiperrealismo", movimiento que busca conseguir una representación más auténtica que la que alcanza a producir una cámara, en la cual puede apoyarse pero sobre la que entiende que ya viene alterada a causa de las características y limitaciones propias del procedimiento fotográfico. 
en la pintura realista, sino que trata de semejarse a una realidad tal y como esta sería representada por una máquina. La aspiración de realismo en el matte painting se define en la intención de "producir imágenes fotográficas por medios no fotográficos" (Darley, 2002, p. 38). Este contexto nos permite ya prescindir del ambiguo término realista que en realidad no consigue describir el carácter analógico del matte painting y afirmar, de un modo mucho más preciso, que lo que el matte painting moviliza es una representación fotorrealista, no una representación de la realidad sino del modo en que una cámara capturaría un determinado motivo inexistente en caso de existir.

Estas consideraciones nos permiten no sólo inscribir al matte painting en la órbita del fotorrealismo sino postular desde aquí al matte painting como posiblemente la forma más habitual de pintura fotorrealista, la que se desarrolla desde hace más tiempo, ya que no surge en la década de 1960 como el citado movimiento sino en 1907, como la forma que ha producido un mayor número de obras fotorrealistas y ha implicado a un número mayor de artistas. Ello nos permite reivindicar al matte painting cinematográfico como una forma destacada, cuando no la prioritaria por extensión temporal y número de obras, de pintura fotorrealista $\left(\mathrm{F}_{4}\right)$.

Pero un paso más adelante nos debe conducir a admitir que la imitación en el matte painting no se circunscribe a la representación fotográfica, sino que debemos ser conscientes de que este ha de tener en consideración además las características de la captura cinematográfica y las particularidades de los procesos de laboratorio implicados en el dispositivo fílmico. Efectivamente, si Metz (2002) afirma, a propósito de los efectos ópticos en la banda de la imagen, que "mientras que las imágenes del film tienen como referentes objetos, los referentes de los efectos ópticos son, de algún modo, las imágenes en sí o, como mínimo, las que les son contiguas en la cadena” ( $p$. 186), de idéntica forma encontramos aquí la pintura tomando como su referente a la imagen rodada, la cual a su vez tiene su referente en la realidad. 
En el matte painting la pintura a quien verdaderamente imita es al cine, y toma prestado de la imagen cinematográfica su referente.

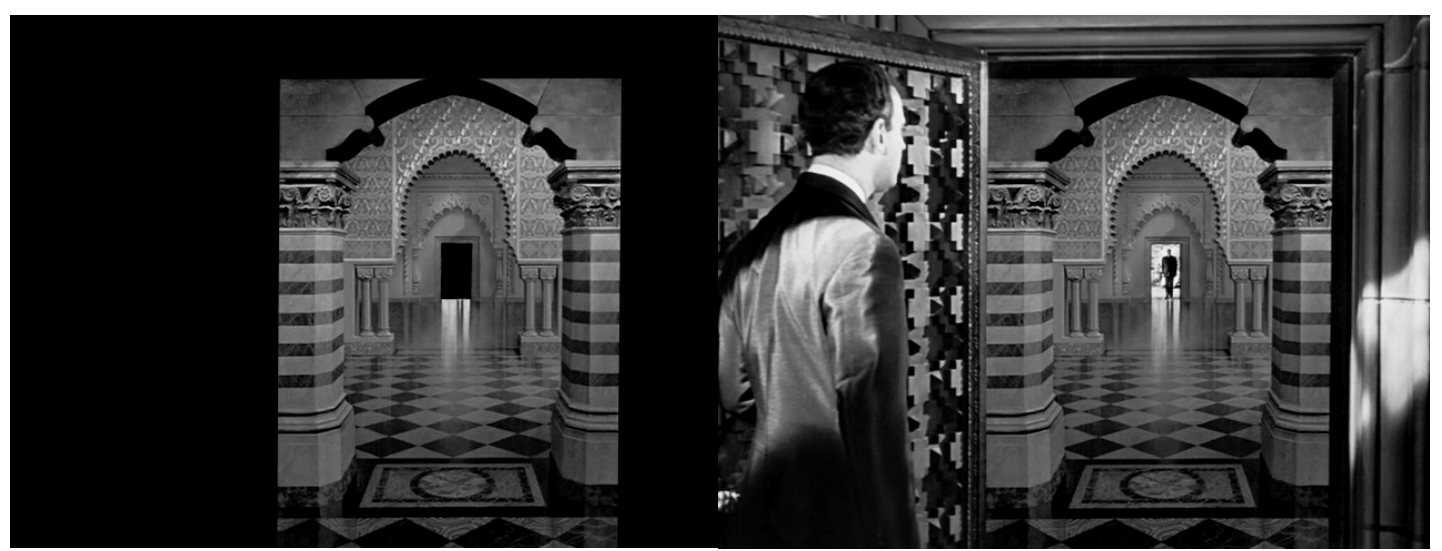

F4. Matte painting de Mario Larrinaga en Ciudadano Kane (Citizen Kane, Orson Welles, 1941).

A este respecto resulta muy ilustrativo observar el trabajo de matte painters como Albert Whitlock o Matthew Yuricich, los cuales, conociendo el particular tratamiento que la captura cinematográfica y los procesos de laboratorio provocan en la imagen, son capaces de pintar alterando la textura, definición y gama tonal de sus matte paintings de modo que muestren la deseada analogía con el metraje rodado no en una contemplación directa, sino una vez que lo pintado es filmado y alterado por dichos procesos de revelado y composición. Esta contemplación del matte painting diferida en el tiempo y en el medio, ya que su observación nunca es directa como en la pintura fotorrealista sino tras su incorporación al metraje fílmico, obliga al matte painter a operar una evaluación muy compleja del aspecto de la obra. El aspecto que se mostrará en la pantalla no es exactamente el que presenta la pintura en una contemplación directa, y la imagen objetivo no es por tanto la que el artista ve ante sus ojos sino el resultado surgido tras un elaborado tratamiento fotoquímico que alterará sensiblemente muchas de sus características aspectuales, debiendo ser capaz de inferir apriorísticamente la apariencia que la obra ofrecerá tras ser procesada. Todo ello nos invita a sugerir el término cinerrealismo, planteado como subgénero dentro del fotorrealismo, para describir esta particular vocación del matte painting por la imitación de la imagen cinematográfica, la aspiración que manifiesta por imitar, más que a la fotografía, a la 
representación propia del dispositivo cinematográfico con todo su mecanismo, actitud que como estamos viendo moviliza unos requerimientos distintos de los del fotorrealismo convencional ( $\left.\mathrm{F}_{5}\right)$.
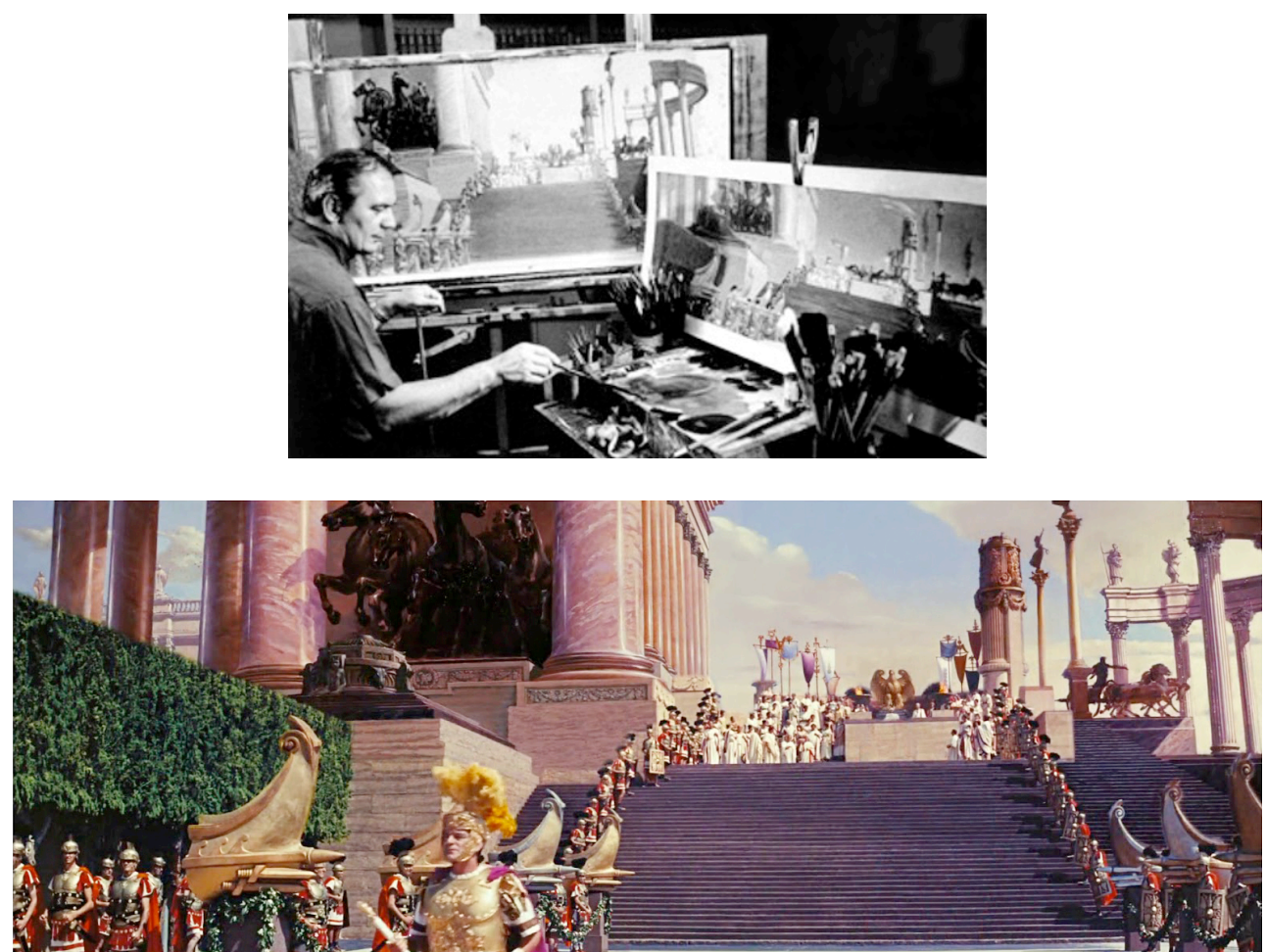

F5. Matte painting de Matthew Yuricich en Ben Hur (William Wyler, 1959).

\section{El matte painter como artista plástico}

Una vez que hemos ubicado el matte painting en el espacio intersección ente dos artes, cine y pintura, cabría formularse la siguiente pregunta: desde un punto de vista cultural, ¿̇sería el matte painting un arte en la misma medida que otras formas de pintura? O, enunciándolo de otra manera, ¿debe considerarse al matte painter un artista de pleno derecho? Obviamente la respuesta a esta pregunta, plagada de matices, pasaría por esclarecer qué prácticas estéticas consideramos arte y dónde se encuentran los límites de tan complejo concepto. En cualquier caso, lo cierto es que tradicionalmente el matte painter ha ocupado una consideración más próxima a la del artesano que a la del autor. Una buena parte de ello se debe, obviamente, a la condición de invisibilidad de esta expresión visual. El buen matte painting 
no llama la atención sobre sí mismo, es transparente a la percepción del espectador, quien no es consciente de estar mirando una pintura y por tanto es inducido a atribuir la autoría de la imagen a otras figuras, como al decorador o al director de fotografía. El film Narciso Negro (Black Narcissus, Michael Powell, 1947) constituye un claro ejemplo de este argumento cuando fue reconocido con el Academy Award a la Mejor Fotografía en Color para su Director de Fotografía, Jack Cardiff, siendo en realidad gran parte del mérito de la espectacularidad visual del film debido a los extraordinarios matte paintings pintados por Walter Percy Day. El propio Cardiff reconocía cuánto de la factura visual de la película había sido en realidad obra de su matte painter:

El gran "Poppa” Day [...] era un auténtico mago con los mattes en cristal en todo tipo de trucaje. Su trabajo en este film fue tan realista que estoy seguro que mucha gente pensó que era mi fotografía y probablemente no hubiera ganado yo el Oscar si hubieran sabido que "Poppa" Day había pintado esos preciosos planos (Vaz \& Barron, 2002, p. 111).

Pero no sólo es transparente el matte painting como efecto, sino que durante mucho tiempo al propio matte painter se le aplicó la misma condición de invisibilidad, impuesta por los propios estudios de producción, quienes durante décadas prefirieron mantener en secreto las técnicas de creación de sus efectos especiales por miedo a perder el interés de sus inversores o cierta ventaja competitiva frente a otros estudios. Transparencia de lo pintado e invisibilidad del oficio que lo realiza.

Sin embargo aún podemos apuntar a una tercera razón todavía más nuclear: aún cuando se visibiliza y reconoce la actividad del matte painter, este tiende generalmente a asociarse más a un artesano de oficio que a un artista de pleno derecho y la razón parece estar relacionada con la inferior consideración que desde un punto de vista cultural se atribuye tradicionalmente a las artes ilusionistas y de simulación, motivada por la creencia errónea de que representan un menor aporte de significado que otras expresiones artísticas. Esto nos recuerda las palabras de Darley (2002) 
en su reivindicación de las también ornamentales y sensuales formas de la nueva estética digital, cuando dice:

¿no podríamos admitir también que lo que puede que aquí se manifieste sean determinadas inquietudes en relación con la destreza técnica (desplegada en la producción de diversos efectos especiales), inquietudes que hasta ahora no se habían comprendido a fondo precisamente porque siempre se las había considerado como inmediatamente transparentes o inferiores? (Darley, 2005, p. 25).

El matte painting, al igual que las manifestaciones de la nueva cultura visual digital de espectáculo que reivindica Darley, pertenece a esta tradición estética, infravalorada como expresión cultural, que privilegia la dimensión externa y formal frente a la semántica y reflexiva, y que despliega su riqueza expresiva en el plano material y sensual. Como el resto de artes de la superficie, la ilusión, la prestidigitación y la simulación, consideradas habitualmente como meramente ornamentales, el matte painting contribuye en buena medida a lo que el receptor admira en su experiencia espectatorial (Darley, 2002, p. 25) y por tanto, como forma de expresión, merece una comprensión mayor de su naturaleza estética y una consideración a la altura de la calidad de su aporte. Junto con Darley (2002), animamos a superar "la perspectiva crítica que los enfoques del pasado aplicaban a estos desarrollos” (p. 25) y a reconocer la complejidad y validez de una práctica como la que nos ocupa, una reflexión que nos obliga a reivindicar la consideración cultural del matte painter como un pintor y artista plástico de pleno derecho, habitando en el medio cinematográfico (F6).

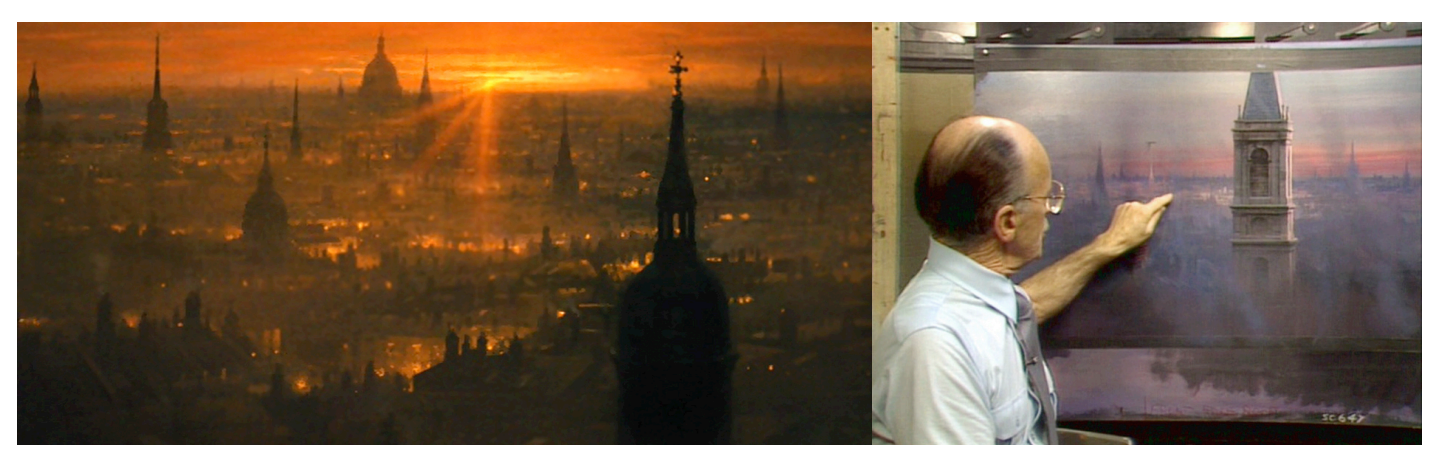

F6. Matte paintings de Peter Ellenshaw en Mary Poppins (Robert Stevenson, 1964). 


\section{Conclusiones}

A lo largo del presente artículo hemos podido constatar cómo el matte painting, en su ambición por mimetizarse con el metraje capturado por la cámara, busca la simulación de una representación fotográfica y, más concretamente, del registro que produce la cámara cinematográfica. Constituye, por tanto, una representación manual que simula haber sido creada por una cámara, lo que nos ha permitido inscribirlo dentro de la órbita del fotorrealismo como práctica artística, de hecho como posiblemente la forma más habitual de pintura fotorrealista, la que se desarrolla desde hace más tiempo, recordemos que surge en 1907, la que ha producido un número mayor de obras fotorrealistas y ha implicado a un mayor número de artistas. Un paso más adelante nos ha llevado a admitir que la imitación en el matte painting no se reduce a la representación fotográfica, sino que debe tener en consideración además las características de la captura fílmica y las particularidades de los procesos de laboratorio implicados en el dispositivo cinematográfico, lo que nos invita a sugerir en este artículo el término cinerrealismo para aludir a la particular vocación del matte painting por la imitación de la imagen cinematográfica, la aspiración que manifiesta por imitar, más que a la fotografía, a la representación propia del dispositivo cinematográfico con todo su mecanismo, actitud que moviliza unos requerimientos distintos de los del fotorrealismo convencional.

Más fructífero incluso ha resultado el análisis en torno a las particulares relaciones entre cine y pintura que se activan en un plano con matte painting. Las consideraciones anteriormente expuestas nos han permitido dejar constancia de cómo dentro del cuadro se establece un intercambio mutuo de aportes entre lo pintado y lo filmado, entre el dibujo y el fotograma, en definitiva entre cine y pintura, en términos que no es fácil encontrar en otros contextos. La superficie del fotograma se convierte en el lugar de encuentro de dos signos icónicos de naturalezas diferentes en el eje de la representación a partir del que se activa una cooperación en servicio de la construcción del significado. La imagen en la percepción del espectador se 
constituye por suma de estas dos entidades, donde ninguna de las dos imágenes es leída en sí misma sino en relación con el significante que producen juntas y el texto que este significante elabora. El matte painting construye, a partir del contenido en la pintura y del contenido en el fotograma, un significado nuevo que emana de la tensión entre ambos. La pintura realiza su aporte proporcionando a la imagen fílmica todo aquello que la cámara no alcanza a retratar mientras la imagen rodada aporta certificado de realidad a lo pintado, un medio permite una representación omnipotente y el otro aporta certificado de realidad a lo representado, principios sobre los que el matte painting asienta su capacidad de simulación y entre los que discurre su efectividad como recurso. Es esta relación simbiótica entre los dos medios y la sólida sutura que esta relación produce la que posibilita aquí el surgimiento del sentido. La imagen resultante es un conglomerado, un híbrido, un montaje, pero esta es una realidad que se nos oculta. Tras la sutura la materia pictórica desaparece para el hecho de la percepción y una imagen nueva ocupa su lugar. La pintura, convertida en recurso transparente, realiza su aporte por ausencia y será la cualidad documental de la materia cinematográfica quien termine por ocultar el trucaje, borrando los procedimientos que lo han producido y evitando que el espectador cuestione la naturaleza de la imagen. La sutura se refuerza por el hecho de que todo espectador conoce con anterioridad el mecanismo registrador del hecho fílmico, el proceso mediante el cual este produce la iconización de una realidad preexistente, y por tanto asume la autenticidad de lo que aquel le ofrece sin cuestionarla.

A la luz de esta perspectiva resulta revelador constatar que el matte painting se configura en términos de relación simbiótica operada en el interior del cuadro, que se convierte en el tejido en el que se entrelazan los aportes, relación de enorme singularidad que hace legítimo afirmar que en el seno del matte painting se produce uno de los diálogos más íntimos, si no el más íntimo, de cuantos se establecen entre el cine y la pintura. 


\section{Referencias bibliográficas}

Aumont, J. (1997). El ojo interminable. Barcelona: Paidós.

Bazin, A. (2008). ¿Qué es el cine? Madrid: Rialp.

Borau, J. L. (2003). La pintura en el cine. El cine en la pintura. Madrid: Ocho y Medio.

Cerrato, R. (2010). Cine y Pintura. Madrid: Ediciones JC.

Darley, A. (2002). Cultura visual digital. Espectáculo y nuevos géneros en los medios de comunicación. Barcelona: Paidós.

Deleuze, G. (1984). La imagen-movimiento. Barcelona: Paidós.

Dubois, P. (1994). El acto fotográfico. Barcelona: Paidós.

Eisenstein, S. (1989). Teoría y técnica cinematográficas. Madrid: Rialp.

Manovich, L. (2005). El lenguaje de los nuevos medios de comunicación. La imagen en la era digital. Barcelona: Paidós Ibérica.

Metz, C. (2002). Ensayos sobre la significación en el cine (1968-1968). Barcelona: Paidós.

Mitry, J. (2002). Estética y psicología del cine. Las estructuras. Madrid: Siglo Veintiuno de España Editores.

Vaz, M. C. \& Barron, C. (2002). The invisible art. San Francisco: Chronicle Books.

Zunzunegui, S. (2010). Pensar la imagen. Madrid: Cátedra. Signo e Imagen. Universidad del Pais Vasco. 